Check for updates

Cite this: RSC Adv., 2019, 9, 25797

Received 21st May 2019

Accepted 11th August 2019

DOI: $10.1039 / c 9 r a 03835 c$

rsc.li/rsc-advances

\section{A new HPLC-UV derivatization approach for the determination of potential genotoxic benzyl halides in drug substances $\dagger$}

\author{
Shunli Ji, (D) ${ }^{\text {ab }}$ Hongbin Gao, $\star^{\mathrm{c}}$ Xingya Xia ${ }^{\mathrm{ab}}$ and Feng Zheng (D) *ab
}

Benzyl halides, widely used as alkylation reagents in drug synthesis, are potential genotoxic impurities (PGTIs) required to be controlled at trace levels. However, the existing analytical methods for benzyl halides often suffer from matrix interferences or low derivatization efficiency of benzyl chlorides. In this paper, a simple derivatization HPLC-UV method was developed for the analysis of these residual trace benzyl halides in drug substances. 1-(4-Nitrophenyl) piperazine (4-NPP) was selected as a new derivatization reagent because it shifted well the benzyl halides derivatives away to the near visible range (392 nm), which could minimize the matrix interferences from the drug substances and related impurities. Meanwhile, potassium iodide (KI) was used to convert the mixed benzyl halides into benzyl iodides before derivatization. The derivatization parameters were also optimized using the design of experiments (DoE) for achieving the best reaction efficiency. The results showed that the new approach had high specificity and sensitivity, and the LOQs were $7-9 \mu \mathrm{g} \mathrm{g}^{-1}$ relative to $5 \mathrm{mg} \mathrm{mL}^{-1}$ antipyrine and 17.5-22.5 $\mathrm{mg} \mathrm{g}^{-1}$ relative to $2 \mathrm{mg} \mathrm{mL}^{-1}$ oroxylin $A$. The method is a valuable alternative for the determination of residual benzyl halides in the drug substances.

\section{Introduction}

Benzyl halides, such as benzyl chloride or benzyl bromide, are of increasing concern to pharmaceutical industries and regulatory agencies due to their potential genotoxicity. ${ }^{1-3}$ Since the use of benzyl halides cannot always be avoided in drug synthesis, ${ }^{4}$ it is necessary to develop efficient and robust methods for monitoring benzyl halides at safe levels in the development and production of drug substances. ${ }^{5}$

There are several analytical techniques for the determination of residual benzyl halides in drug substances. Headspace gas chromatography (HS-GC) has become a common technique for the analysis of alkyl halides in drug substances. ${ }^{5}$ However, the traditional HS diluents are not applicable for high-boiling benzyl halides. Ionic liquids (ILs) have been used as diluents for the determination of high-boiling alkylation compounds, whereas they were relatively expensive diluents for routine analysis. ${ }^{6}$ Chemical derivatization combined with

${ }^{a}$ Key Laboratory of Drug Quality Control and Pharmacovigilance, Ministry of Education, China Pharmaceutical University, 24 Tongjiaxiang, Nanjing 210009, China. E-mail: cpu_analyst@126.com

${ }^{b}$ Department of Pharmaceutical Analysis, China Pharmaceutical University, 24 Tongjiaxiang, Nanjing 210009, China

${ }^{c}$ Department of Pharmacy, Baoshan Branch of Renji Hospital, School of Medicine, Shanghai Jiao Tong University, Shanghai 200444, China

† Electronic supplementary information (ESI) available. See DOI: 10.1039/c9ra03835c

\$ These two authors contributed equally to this article.
MS-based techniques has been employed for increasing the sensitivity of benzyl halides. ${ }^{7-9}$ The nucleophilic reagents including 4-dimethylaminopyridine and butyl 1-(pyridin-4-yl) piperidine 4-carboxylate have been reported as derivatization reagents. However, the main obstacle of these MS-based methods is the lower derivatization efficiency for benzyl chlorides, which needs long reaction time ( $\geq 4 \mathrm{~h})$ to achieve the required sensitivity. These existing methods are summarized in the ESI (Table S1 $\dagger$ ).

Direct HPLC-UV technique for benzyl halides analysis often suffers from the matrix interferences of the drug substances. Recently, derivatization HPLC-UV approach with the detection wavelength above $380 \mathrm{~nm}$ has become popular for the control and analysis of potential genotoxic impurities (PGTIs), because most of the drug substances and related impurities exhibit weak absorption at that region. ${ }^{\mathbf{1 0 - 1 2}} \mathrm{A}$ red shift of the UV maximum wavelength generates when electron donor groups (such as $-\mathrm{NH}_{2},-\mathrm{NH}-,-\mathrm{NH}-\mathrm{NH}_{2}$ ) and electron withdrawing groups $\left(-\mathrm{NO}_{2}\right)$ are at the $o$-position and/or $p$-position of benzene ring. ${ }^{13}$ Thus, in this paper, we have systematically compared these derivatization reagents for the determination of benzyl halides by the HPLC-UV method. Meanwhile, potassium iodide (KI) was used to convert the mixed benzyl halides into benzyl iodides before derivatization. Finally, a simple and sensitive derivatization HPLC-UV method was developed and validated for the determination of residual benzyl halides in the drug substances. 


\section{Experimental}

\subsection{Chemicals and reagents}

1-(4-Nitrophenyl) piperazine (4-NPP, 98\%), methyl 4-(bromomethyl) benzoate (4-BMB, 98\%), 2-chlorobenzyl chloride (2CBC, 98\%), 4-chlorobenzyl chloride (4-CBC, 98\%) and 2,6dichlorobenzyl bromide (2,6-DCB, 98\%) were obtained from Energy Chemical (Shanghai, China). 1-(2-Nitrophenyl)piperazine (2-NPP, 98\%) and benzyl chloride (BC, 99\%) were purchased from the TCI Development Co. Ltd (Shanghai, China). Benzyl bromide (BB, 98\%) was obtained from the Macklin Biochemical Co. Ltd (Shanghai, China). 2-Nitrophenylhydrazine (2-NPH, 97\%) and potassium iodide (KI, 99\%) were purchased from Aladdin (Shanghai, China). 2-Nitroaniline (2-NA, 98.5\%) and 4-nitroaniline (4-NA, 98\%) were obtained from Sinopharm Chemical Reagent Co. Ltd (Shanghai, China). Oroxylin A was synthesized as the active pharmaceutical ingredient in the Department of Medicinal Chemistry, China Pharmaceutical University (Nanjing, China). ${ }^{14}$ Antipyrine was purchased from Sinopharm group Co. Ltd (Shanghai, China) as the active pharmaceutical ingredient. The structures of these compounds are shown in Fig. 1. Water was purified using a Millipore Milli-Q system (Bedford, MA, USA). HPLC grade acetonitrile was obtained from TEDIA (Fairfield, USA). All other reagents were of analytical grade and obtained from conventional commercial sources.

\subsection{Instrumentation and chromatographic conditions}

The experiments were performed on a Shimadzu LC-20AT series HPLC system (Kyoto, Japan) with a SPD-20A UV detector. A LCsolution workstation (Shimadzu, Kyoto, Japan) was used to control the system and date acquisition. An InertSustain ${ }^{\circledR}$ C18 column $(250 \mathrm{~mm} \times 4.6 \mathrm{~mm}, 5 \mu \mathrm{m})$ was used for the analysis. The mobile phase was composed of acetonitrile (solvent A) and $5 \mathrm{mM}$ ammonium acetate solution (solvent B). The chromatographic separation was achieved using the following gradient elution: $0-10 \mathrm{~min}, 70 \% \mathrm{~A} ; 10-15 \mathrm{~min}$, ramping from $70 \%$ to $85 \% \mathrm{~A} ; 15-20 \mathrm{~min}, 85 \% \mathrm{~A}$, with a constant flow rate of 1.0 $\mathrm{mL} \min ^{-1}$. The column temperature was kept at $30{ }^{\circ} \mathrm{C}$. The typical injection volume was $20 \mu \mathrm{L}$.

\subsection{Preparation of solutions}

Separate solutions of 2-NPH, 2-NA, 4-NA, 2-NPP and 4-NPP at the concentration of $3 \mathrm{mg} \mathrm{mL}{ }^{-1}$ were freshly prepared in acetonitrile for the derivatization experiments. A standard stock solution of KI was freshly prepared each day by dissolved KI (2.0 g) in water $(10 \mathrm{~mL})$. Separate stock solutions containing $1 \mathrm{mg}$ $\mathrm{mL}^{-1}$ of each benzyl halides were prepared in acetonitrile. Before use, a series of mixed standard working solutions (0.1-1 $\mu \mathrm{g} \mathrm{mL} \mathrm{L}^{-1}$ ) were prepared by diluting each stock solution with the same solvent.

\subsection{Derivatization}

Accurately remove $4 \mathrm{~mL}$ of mixed standard working solutions, place it in a $10 \mathrm{~mL}$ vial, add $1 \mathrm{~mL}$ of $200 \mathrm{mg} \mathrm{mL}^{-1} \mathrm{KI}$ solution (the final concentration of $\mathrm{KI}$ is $40 \mathrm{mg} \mathrm{mL} \mathrm{L}^{-1}$ ), shake well, and react in a $60{ }^{\circ} \mathrm{C}$ water bath for $30 \mathrm{~min}$. Then, $1 \mathrm{~mL}$ of the derivatization reagent solution were added to the same $10 \mathrm{~mL}$ vial. After being vortexed for $10 \mathrm{~s}$ and diluted to $10 \mathrm{~mL}$ with acetonitrile, the mixture was allowed to react at $60^{\circ} \mathrm{C}$ water bath for $90 \mathrm{~min}$. The reaction solution was analyzed by HPLC-UV directly and the injection volume was $20 \mu \mathrm{L}$. For application, $4 \mathrm{~mL}$ of oroxylin $\mathrm{A}\left(5 \mathrm{mg} \mathrm{mL} \mathrm{m}^{-1}\right)$ or antipyrine $\left(12.5 \mathrm{mg} \mathrm{mL}^{-1}\right)$ in acetonitrile replaced the $4 \mathrm{~mL}$ of mixed standard working solutions and the other step was the same. The derivatization scheme of benzyl halides with 4-NPP is shown in Fig. 2.

\subsection{Method validation}

To demonstrate the feasibility of the newly developed method, validation was performed under the optimal conditions in relation to specificity, linearity, limit of quantitation (LOQ), limit of detection (LOD), precision, accuracy and stability. These validation parameters were validated according to the ICH guidelines ${ }^{15}$ and Chinese Pharmacopoeia. ${ }^{16}$

Oroxylin A and antipyrine were used as the representative drug substances. Since the analytical method implications were that the limits could be 10 times greater than the default lifetime TTC (threshold of toxicological concern) limit (1.5 $\mu \mathrm{g}$ per day), ${ }^{17} 15 \mu \mathrm{g}$ per day was selected as the TTC of the study. Calculation of the limit applied for benzyl halides is as follows: the TTC value divided by the maximum daily dose ( $\mathrm{g}$ per day). ${ }^{18}$ Based on the maximum daily dose for both antipyrine and oroxylin A of $600 \mathrm{mg}$ per day, their GTIs are required to be controlled at a concentration limit of $25 \mu \mathrm{g} \mathrm{g}^{-1} .^{19,20}$

\section{Results and discussion}

\subsection{Selection of derivatization reagents}

Since 2-NPH has been reported as a suitable derivatization reagent for detecting acyl chlorides in the near visible range $(395 \mathrm{~nm}),{ }^{11}$ the UV spectrum of benzyl halides after derivatization with 2-NPH was studied firstly. Fig. 3A showed that the maximum absorption wavelength of derivatization product was just $261 \mathrm{~nm}$, which was not suitable for benzyl halides analysis. Hence, a new derivatization reagent was urgently needed.

Nitroaniline (NAs) and nitrophenylhydrazine (NPPs) are two other kinds of potential derivatization reagents with the maximum absorbance wavelength in the near visible range. ${ }^{13}$ The results showed that the derivatization reaction between benzyl bromide and NAs (2-NA, 4-NA) hardly proceeded. It may be attributed to the strong conjugation of nitrobenzene group, leading to the weaker nucleophilic ability of amine $\left(-\mathrm{NH}_{2}\right)$ in the NAs structures. On the contrary, because the aliphatic amine $\left(-\mathrm{NH}^{-}\right)$was far away from the nitrobenzene ring in the NPPs structures, the reaction rates between NPPs (2-NPP, 4NPP) and benzyl bromide were much higher. Furthermore, the derivatization product of 4-NPP stood out given that it exhibited strong absorption at $392 \mathrm{~nm}$ (Fig. 3B, the red line) compared with that of 2-NPP (Fig. 3B, the black line). Other selected benzyl halides showed similar spectral characteristics (Fig. S1†). In order to further verify that the red shift effect of the reaction of 
(A)<smiles>ClCc1ccccc1</smiles>

Benzyl chloride (BC)<smiles>Clc1cccc(Cl)c1CBr</smiles><smiles>ClCc1ccccc1Cl</smiles>

2-Chlorobenzyl chloride (2-CBC)<smiles>ClCc1ccc(Cl)cc1</smiles>

4-Chlorobenzyl chloride (4-CBC)

2,6-Dichlorobenzyl bromide (2,6-CB)<smiles>BrCc1ccccc1</smiles><smiles>COC(=O)c1ccc(CBr)cc1</smiles>

\section{(B)}<smiles>Nc1ccccc1[N+](=O)[O-]</smiles>

2-Nitroaniline (2-NA)<smiles>Nc1ccc([N+](=O)[O-])cc1</smiles>

4-Nitroaniline (4-NA)<smiles>NNc1ccccc1[N+](=O)[O-]</smiles>

2-Nitrophenylhydrazine (2-NPH)<smiles>O=[N+]([O-])c1ccccc1N1CCNCC1</smiles><smiles>O=[N+]([O-])c1ccc(N2CCNCC2)cc1</smiles>

1-(2-nitrophenyl) piperazine (2-NPP)

1-(4-nitrophenyl) piperazine (4-NPP)

(C)<smiles>COc1c(O)cc2oc(-c3ccccc3)cc(=O)c2c1O</smiles>

Oroxylin A<smiles>Cc1cc(=O)n(-c2ccccc2)n1C</smiles>

Antipyrine

Fig. 1 Structures of (A) selected benzyl halides (BC, 2-CBC, 4-CBC, 2,6-CB, BB and 4-BMB), (B) derivatization reagents (4-NPP, 2-NA, 2NPH, 4NA and 2-NPP) and (C) two model drugs (oroxylin A and antipyrine).

benzyl halide with 1-(4-nitrophenyl)piperazine can improve the specificity of the method, chromatograms of oroxylin A at different absorption wavelengths were recorded and compared. It can be seen from Fig. S2 $\uparrow$ that compared with the low wavelength, the detection wavelength at $392 \mathrm{~nm}$ could effectively reduce the matrix interference caused by the drug substance and obtain a smoother baseline. Therefore, 4-NPP was finally chosen for the following study.

\subsection{Conversion of benzyl chlorides}

Because benzyl chlorides showed low reaction efficiency with 4NPP when compared with benzyl bromides or benzyl iodides
(Fig. 4), conversion of benzyl chlorides before derivatization was studied to improve the derivatization efficiency of benzyl chlorides. The direct HPLC-UV $(254 \mathrm{~nm})$ method was used to detect the conversion of benzyl chloride to benzyl bromide or benzyl iodide without the drug matrix.

As shown in Fig. S3(A), $\uparrow$ benzyl chloride could be completely converted to benzyl iodide by KI, while there is still a small peak of benzyl chloride in the HPLC chromatogram after reaction with KBr. Meanwhile, benzyl bromide also could be completely converted to benzyl iodide by KI based on the chromatogram in Fig. S3(B). $\dagger$ To achieve good reaction efficiency, reaction time and reaction temperature were also studied and optimized (see Fig. S4†). Therefore, the mixed benzyl chlorides and benzyl 
<smiles>[X]Cc1ccccc1</smiles>

(X: $\mathrm{Cl}$ or $\mathrm{Br}$ )

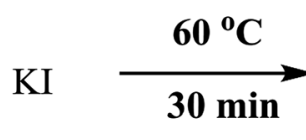<smiles>[R][X]1([H])C=CC=CC1CC</smiles>

$+\mathrm{KX}$

(A)

(X: $\mathrm{Cl}$ or $\mathrm{Br}$ )

$60^{\circ} \mathrm{C}$

$90 \mathrm{~min}$

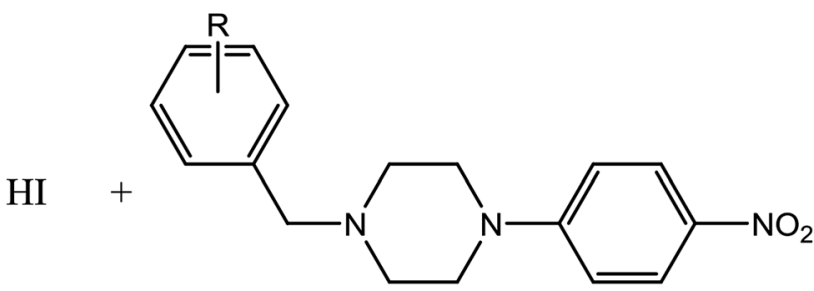

(B)

Fig. 2 Derivatization reactions of benzyl halides $(\mathrm{X}=\mathrm{Cl}, \mathrm{Br})$ with derivatization reagent 4-NPP $(\mathrm{B})$ in the presence of $\mathrm{KI}(\mathrm{A})$.

bromides reaction with $40 \mathrm{mg} \mathrm{mL} \mathrm{m}^{-1} \mathrm{KI}$ in a water bath at $60{ }^{\circ} \mathrm{C}$ for 30 minutes was used before the derivatization with 4-NPP. As shown in Fig. 4, a high reaction efficiency of benzyl chloride with 4-NPP was observed when KI was used as the reactant before derivatization.

\subsection{Optimization of derivatization parameters}

DoE, an advanced system optimization method, has attracted increased attention in the field of analytical chemistry. ${ }^{21,22}$ Thus, based on the single factor experiments (Fig. S5 in the ESI $\dagger$ ), the concentration of 4-NPP $(C)$, reaction time $(t)$ and reaction temperature $(T)$, were chosen as the factors for a central composite face (CCF) DoE by using the software Design-Expert 8.0.5b (Stat-Ease Inc., Minneapolis, USA).
Take the peak area of each derivatization product as the response, the ranges of each factor and the responses were given in Table 1 . The data obtained from 20 runs were investigated by regression analysis, and five quadratic models were developed. The obtained model fit $\left(R^{2}\right)$ was over 0.93 and the predictability $\left(Q^{2}\right)$ was higher than 0.86 , meaning that the models were appropriate (see more details in the Table S2 $\dagger$ ). Take the model of 4-BMB derivative (Peak Area 1) as representative. Fig. 5 showed the regression coefficients of the quadratic model 1 of 4-BMB derivative (Peak Area 1) and their confidence intervals. Fig. 6 showed the dependence of Peak Area 1 on $C-T$ and $T-t$ variable pairs. Other four models could be found in the ESI (Fig. S6 and S7†).
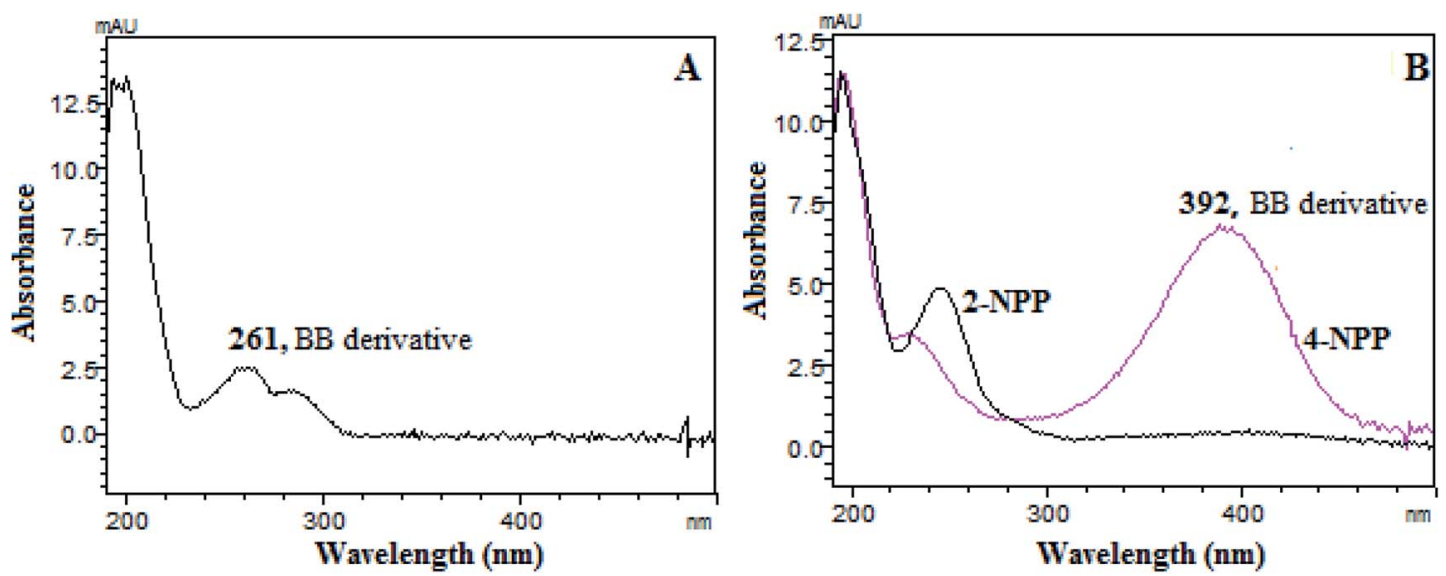

Fig. 3 UV spectrums of BB derivatives using 2-NPH (A), 2-NPP (B, the black curve) and 4-NPP (B, the red curve) as the derivatization reagents. The spiking level of 2-NPH, 2-NPP and 4-NPP were all $300 \mu \mathrm{g} \mathrm{mL}^{-1}$. All the derivatization reactions were in a water bath of $60{ }^{\circ} \mathrm{C}$ for $60 \mathrm{~min}$. 


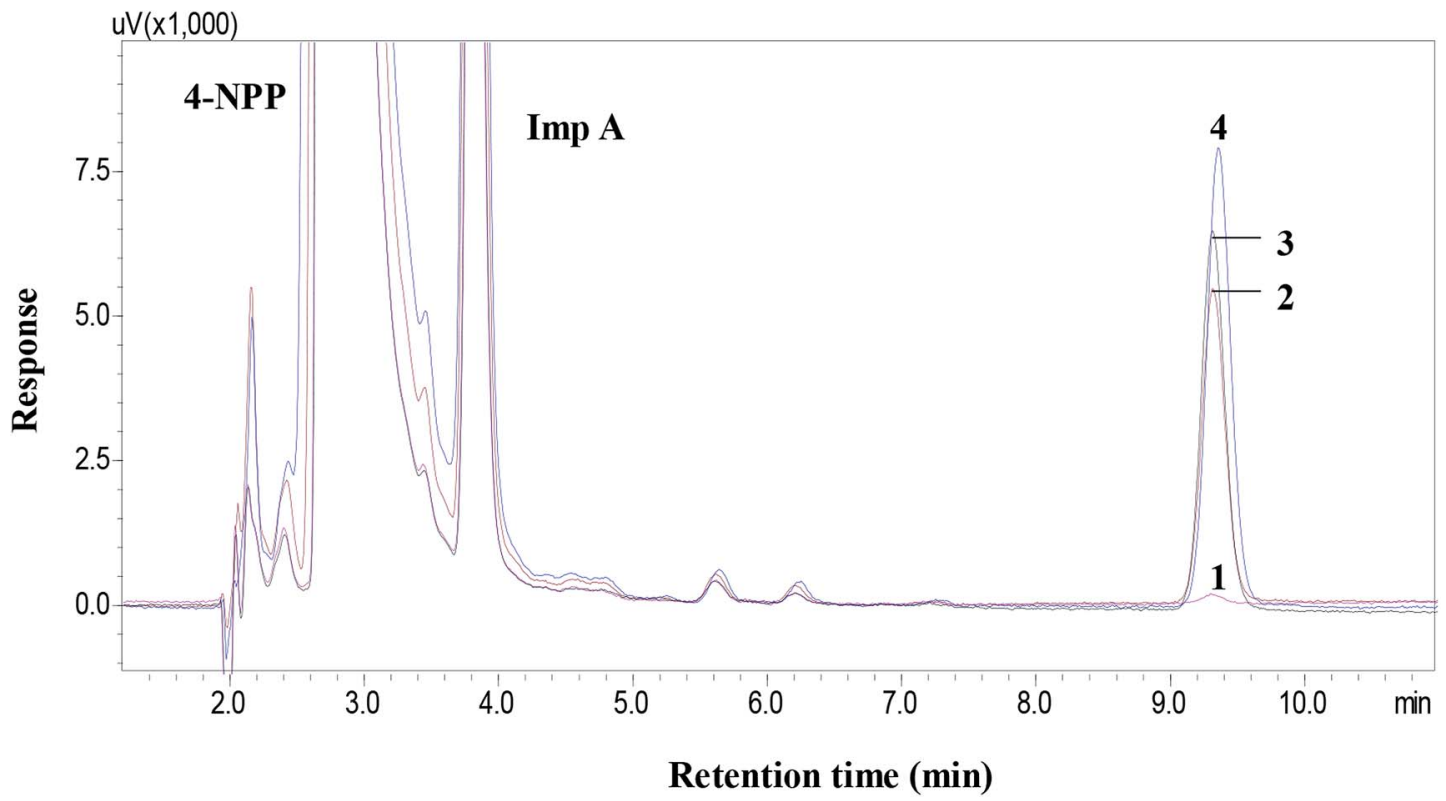

Fig. 4 Typical HPLC chromatograms of benzyl chloride (1), benzyl bromide (2), benzyl iodide (3) and benzyl chloride $+\mathrm{KI}$ (4) after derivatization with 4-NPP in a water bath of $60{ }^{\circ} \mathrm{C}$ for $60 \mathrm{~min}$. The structures of the four derivatization products were the same. Impurity A was the inherent impurity from 4-NPP. The concentration of each benzyl halide was $1 \mu \mathrm{g} \mathrm{mL}^{-1}$.

Table 1 Overview of selected factors with their ranges and responses for experimental design ${ }^{a}$

\begin{tabular}{lll}
\hline Parameter & Range & Response \\
\hline$C$ & $100-500 \mu \mathrm{g} \mathrm{mL} \mathrm{m}^{-1}$ & Peak Area 1-5 \\
$T$ & $25-85{ }^{\circ} \mathrm{C}$ & \\
$t$ & $30-150 \mathrm{~min}$ &
\end{tabular}

${ }^{a}$ Peak Area 1-5 represent the peak areas of 4-BMB derivative, $\mathrm{BB}$ and $\mathrm{BC}$ derivative, 4-CBC derivative, 2 -CBC derivative and 4-BMB derivative, respectively.

After establishing the design space by the optimization function of the software, the optimal parameters were chosen. Results showed it was desirable to set the optimal parameters as

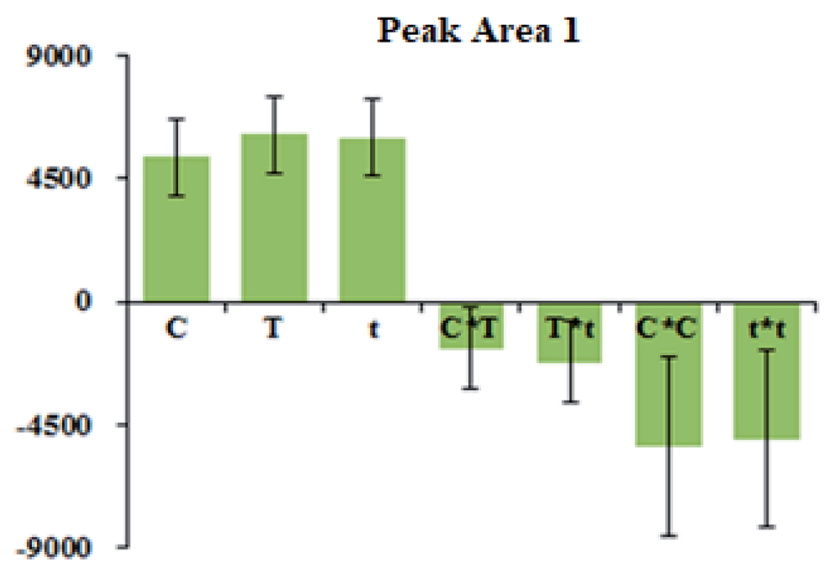

Fig. 5 Regression coefficient plot of Peak Area 1 for the CCF design of the DoE method development. follows: $300 \mu \mathrm{g} \mathrm{mL}{ }^{-1}$ for the concentration of 4 -NPP $(C), 60{ }^{\circ} \mathrm{C}$ for reaction temperature $(T)$ and $90 \mathrm{~min}$ for reaction time $(t)$.

\subsection{Specificity of the method}

The specificity was investigated according to the chromatograms of derivatization reagent and drug substances on the separation of target derivatization products. Fig. 7 showed that the mixed benzyl halide derivatives were well separated from derivatization reagent, drug substances and related impurities. It was observed that the chromatogram at $392 \mathrm{~nm}$ exhibited smooth baseline and less matrix interference from the drug substance and related impurities. The results show that the proposed method was of highly specificity.

\subsection{Linearity and correlation coefficient}

The linearity was performed by diluting the benzyl halides stock solutions to the required concentrations. The derivatization solutions were prepared at six concentration levels, each in triplicate and construct calibration plots. As shown in Table 2, within the linear ranges of $40-400 \mathrm{ng} \mathrm{mL}{ }^{-1}$ for $4-\mathrm{BMB}, \mathrm{BB}, \mathrm{BC}$ and 2,6-DCB, 50-400 ng $\mathrm{mL}^{-1}$ for 4-CBC, 2-CBC, the present method exhibit good linearity for all six benzyl halides and the linear regression fits of which were all above 0.999 .

\subsection{Sensitivity}

The sensitivity of the method is generally expressed as the limit of detection (LODs) and limit of quantitation (LOQs). In this study, LODs and LOQs were estimated as three and ten times the signal-to-noise $(\mathrm{S} / \mathrm{N})$ ratio, respectively. The data are given in Table 2. The LODs of six benzyl halides ranged from 15-20 ng $\mathrm{mL}^{-1}$, while the LOQs were in the range of $35-45 \mathrm{ng} \mathrm{mL} \mathrm{m}^{-1}$, 
A

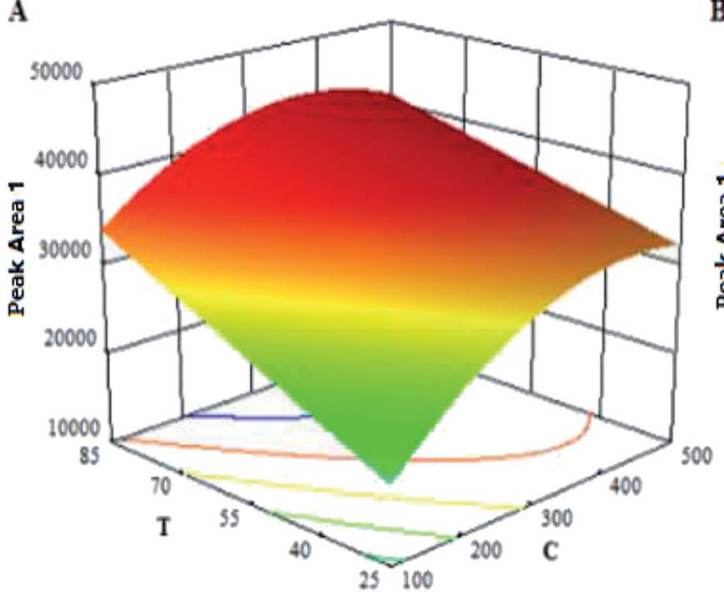

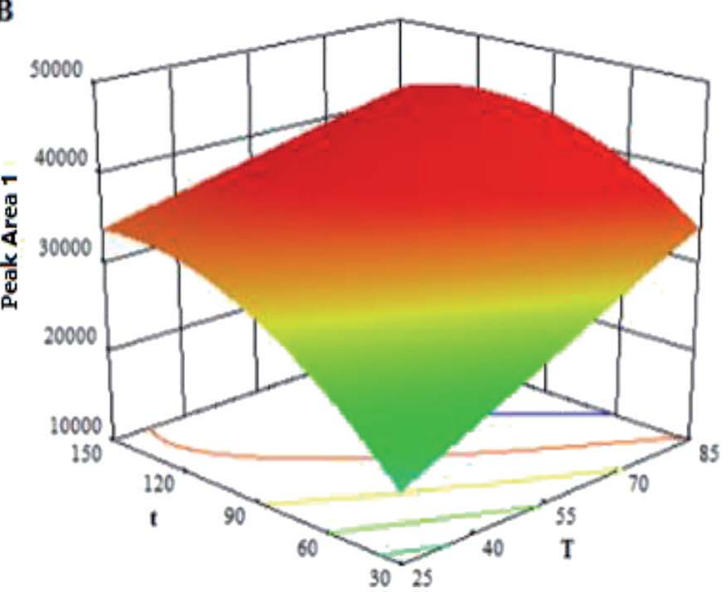

Fig. 6 Dependence of Peak Area 1 on C, $T$ and $t$. The concentration of 4-BMB was $400 \mathrm{ng} \mathrm{mL}^{-1}$.

equivalent to $7-9 \mu \mathrm{g} \mathrm{g}^{-1}$ relative to $5 \mathrm{mg} \mathrm{mL}^{-1}$ antipyrine and 17.5-22.5 $\mu \mathrm{g} \mathrm{g}^{-1}$ relative to $2 \mathrm{mg} \mathrm{mL}^{-1}$ oroxylin A, meeting the limit requirements.

\subsection{Precision and stability}

The precision was assessed by injecting six replicates of mixed derivatization solutions of $4 \mathrm{LOQS}$ (the analyte level was below $0.01 \%$ ), and the percent relative standard deviation (\% RSD) was less than $2.84 \%$. The solution stability of 4 -NPP-benzyl halides derivative was also acceptable over a period of $6 \mathrm{~h}$ at room temperature with the RSD\% values below $2.76 \%$. This results indicated that good precision and adequate stability for the determination of benzyl halides in the drug substances.

\subsection{Recovery}

The recovery experiments were conducted in three spiking levels (LOQs, 4LOQs, 10LOQs) of the mixed benzyl halides in the two drug substances. Based on different solubility of the examined samples, spiked sample solutions of antipyrine $(5 \mathrm{mg}$ $\left.\mathrm{mL}^{-1}\right)$ and oroxylin $\mathrm{A}\left(2 \mathrm{mg} \mathrm{mL} \mathrm{m}^{-1}\right)$ were prepared. The mean recoveries were calculated as: recovery $(\%)=100 \times\left(C-C_{\mathrm{o}}\right) / C_{\mathrm{s}}$, where $C$ represents the total concentration after derivatization, $C_{\mathrm{o}}$ represents the original concentration in the drug substance, $C_{\mathrm{s}}$ represents the spiked concentration. Good recoveries in the range of $95.7-103.9 \%$ were obtained for these analytes with the RSD\% below $3.97 \%$. The results were summarized in Table 3 . Therefore, above data indicated that the proposed method was reliable for quantifying the benzyl halides in drug substances.

\subsection{Application}

The developed method was then applied for the determination of residual benzyl halides in antipyrine and oroxylin A. As shown in Fig. $7 \mathrm{~b}$ and c, there was no observable peak of derivatization products appeared in the two sample solutions. Although benzyl halides in antipyrine and oroxylin A could not

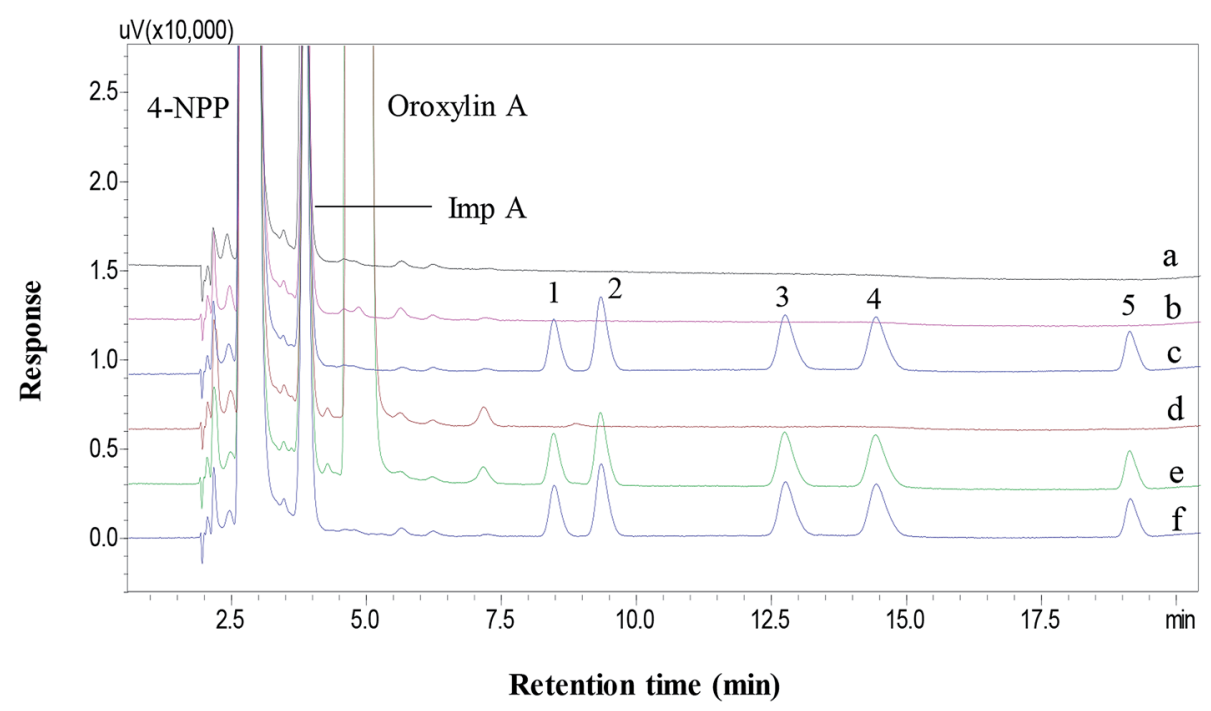

Fig. 7 HPLC chromatograms of the blank derivatization reagent (4-NPP, (a)), antipyrine (b), antipyrine + benzyl halides (c), oroxylin A (d), oroxylin $A+$ benzyl halides (e) and the mixed benzyl halides (f) after derivatization with 4-NPP $\left(300 \mu \mathrm{g} \mathrm{mL}^{-1}\right)$ at $392 \mathrm{~nm}$. Five derivatives products: 4-BMB derivative (1), $B B$ and $B C$ derivative (2), 4-CBC derivative (3), 2-CBC derivative (4) and 2,6-DCB derivative (5). 
Table 2 Validation of the method for the determination of mixed benzyl halides ${ }^{a}$

\begin{tabular}{|c|c|c|c|c|c|c|c|c|c|}
\hline \multirow[b]{2}{*}{ Analyte } & \multirow[b]{2}{*}{ Regression equation } & \multirow{2}{*}{$\begin{array}{l}\text { Linear range } \\
\left(\mathrm{ng} \mathrm{mL}^{-1}\right)\end{array}$} & \multirow[b]{2}{*}{$r$} & \multicolumn{2}{|c|}{$\begin{array}{l}\text { Oroxylin A } \\
\left(\mu g g^{-1}\right)\end{array}$} & \multicolumn{2}{|c|}{$\begin{array}{l}\text { Antipyrine } \\
\left(\mu g g^{-1}\right)\end{array}$} & \multirow[b]{2}{*}{ Precision RSD\% } & \multirow[b]{2}{*}{ Stability RSD\% } \\
\hline & & & & LOD & LOQ & LOD & LOQ & & \\
\hline 4-BMB & $y=109.94 x-1463.7$ & $40-400$ & 0.9994 & 7.5 & 20 & 3 & 8 & 1.74 & 1.21 \\
\hline $\mathrm{BB}+\mathrm{CB}$ & $y=170.33 x-1509.0$ & $40-400$ & 0.9994 & 7.5 & 20 & 3 & 8 & 0.89 & 1.29 \\
\hline 4-CBC & $y=151.74 x-3071.2$ & $50-400$ & 0.9994 & 10 & 22.5 & 4 & 9 & 2.84 & 1.82 \\
\hline 2-CBC & $y=162.91 x-2812.4$ & $50-400$ & 0.9997 & 10 & 22.5 & 4 & 9 & 0.93 & 2.76 \\
\hline $2,6-\mathrm{DCB}$ & $y=103.10 x-877.9$ & $40-400$ & 0.9997 & 7.5 & 17.5 & 3 & 7 & 2.44 & 1.08 \\
\hline
\end{tabular}

Table 3 Recovery data for the determination of benzyl halides in the drug substances

\begin{tabular}{|c|c|c|c|}
\hline Compounds & LOQs recovery (\%) & 4LOQs recovery $(\%)$ & 10LOQs recovery $(\%)$ \\
\hline \multicolumn{4}{|c|}{ Oroxylin $\left(2 \mathrm{mg} \mathrm{mL^{-1 }}\right)$} \\
\hline 4-BMB & $99.4 \pm 1.75$ & $97.8 \pm 0.65$ & $95.7 \pm 2.22$ \\
\hline $\mathrm{BB}+\mathrm{CB}$ & $95.7 \pm 3.69$ & $98.3 \pm 2.32$ & $97.9 \pm 2.31$ \\
\hline $4-\mathrm{CBC}$ & $101.4 \pm 1.33$ & $100.7 \pm 1.45$ & $100.2 \pm 0.58$ \\
\hline 2-CBC & $102.6 \pm 2.63$ & $99.6 \pm 0.62$ & $100.4 \pm 0.72$ \\
\hline 2,6-DCB & $99.3 \pm 1.71$ & $97.0 \pm 0.88$ & $98.5 \pm 1.47$ \\
\hline \multicolumn{4}{|c|}{ Antipyrine $\left(5 \mathrm{mg} \mathrm{mL}^{-1}\right)$} \\
\hline 4-BMB & $103.9 \pm 2.53$ & $101.6 \pm 1.30$ & $99.2 \pm 0.88$ \\
\hline $\mathrm{BB}+\mathrm{CB}$ & $101.0 \pm 2.57$ & $101.3 \pm 1.72$ & $99.3 \pm 0.86$ \\
\hline 4-CBC & $99.4 \pm 1.46$ & $98.9 \pm 0.92$ & $100.1 \pm 0.43$ \\
\hline 2-CBC & $102.6 \pm 3.97$ & $103.8 \pm 0.97$ & $99.4 \pm 0.44$ \\
\hline 2,6-DCB & $96.7 \pm 1.90$ & $99.8 \pm 0.31$ & $98.8 \pm 0.77$ \\
\hline
\end{tabular}

be detected in our report, the method still has the potential to analyze residual benzyl halides in other drug substances.

\section{Conclusion}

The trace level analysis of six benzyl halides in drug substances has successfully been developed by using derivatization HPLCUV method. 4-NPP was chosen as a new suitable derivatization reagent for the determination of residual benzyl halides in the drug substances, since the derivatives showed strong absorption at the wavelength of $392 \mathrm{~nm}$, which could largely improve the specificity of HPLC method. Meanwhile, KI was selected to convert the mixed benzyl halides into benzyl iodides before derivatization. The validation and application results showed that this method was a valuable alternative for the determination of residual benzyl halides in the drug substances.

\section{Conflicts of interest}

There are no conflicts to declare.

\section{Acknowledgements}

This work was financially supported by the Priority Academic Program Development of Jiangsu Higher Education Institutions and the Open Project Program of MOE Key Laboratory of Drug
Quality Control and Pharmacovigilance (No. DQCP2015MS04, No. DQCP2017QN02). Also thanks for the support from National Natural Science Foundation of China (No. 81703472).

\section{Notes and references}

1 R. Benigni and C. Bossa, Chem. Rev., 2011, 111, 2507-2536. 2 D. Q. Liu, S. Mingjiang and A. S. Kord, J. Pharm. Biomed. Anal., 2010, 51, 999-1014.

3 G. Szekely, A. D. S. Mc, M. Gil, F. F. Castelo and W. Heggie, Chem. Rev., 2015, 115, 8182.

4 D. P. Elder and A. Teasdale, Org. Process Res. Dev., 2015, 19, 1437-1446.

5 R. P. Frost, M. S. Hussain and A. R. Raghani, J. Sep. Sci., 2003, 26, 1097-1103.

6 T. D. Ho, P. M. Yehl, N. P. Chetwyn, J. Wang, J. L. Anderson and Q. Zhong, J. Chromatogr. A, 2014, 1361, 217-228.

7 A. M. Wijk Van, B. Beerman, H. A. G. Niederländer, A. H. G. Siebum and G. J. Jong De, Anal. Bioanal. Chem., 2011, 400, 1375-1385.

8 A. M. V. Wijk, H. A. G. Niederländer, A. H. G. Siebum, M. A. T. Vervaart and G. J. D. Jong, J. Pharm. Biomed. Anal., 2013, 74, 133-140.

9 A. M. Wijk Van, H. A. G. Niederländer, M. D. Ogten Van and G. J. Jong De, Anal. Chim. Acta, 2015, 874, 75-83. 
10 D. Hou, J. Fan, L. Han, X. Ruan, F. Feng, W. Liu and F. Zheng, J. Chromatogr. A, 2016, 1438, 46-56.

11 X. Zheng, L. Luo, J. Zhou, X. Ruan, W. Liu and F. Zheng, J. Pharm. Biomed. Anal., 2017, 140, 327-333.

12 J. Wang, S. Yang and K. Zhang, J. Pharm. Biomed. Anal., 2016, 126, 141-147.

13 M. M. Islam, M. D. H. Bhuiyan, T. Bredow and A. C. Try, Comput. Theor. Chem., 2011, 967, 165-170.

14 Z. Li, W. Fu, B. Yang, Q. Guo and Q. You, CN Pat., 101508689 B, 2010.

$15 \mathrm{ICH}$, International Conference on Harmonization Tripartite Guideline, 2005.
16 C. Pharmacopoeia, Chinese Pharmacopoeia Commission, 2015.

17 ICH, Guideline M7, 2014.

18 EMEA guidelines Limits for Genotoxic Impurities EMEA/ CHMP/QWP/251334/2006.

19 B.-B. Yang, N. J. Hounslow, A. J. Sedman and S. T. Forgue, J. Clin. Pharmacol., 1996, 36, 356-360.

20 H. Hui, X. Zhang, H. Li, X. Liu, L. Shen, Y. Zhu, J. Xu, Q. Guo and N. Lu, J. Cancer Res. Clin. Oncol., 2016, 142, 1449-1459. 21 G. Székely, B. Henriques, M. Gil, A. Ramos and C. Alvarez, J. Pharm. Biomed. Anal., 2012, 70, 251-258.

22 G. Székely, B. Henriques, M. Gil and C. Alvarez, Drug Test. Anal., 2014, 6, 898-908. 